\title{
PARTICIPATORY OBSERVATION IN MADRASAH ALIYAH AS A REFERENCE OF LEARNING MODELS IN ERA 4.0
}

\author{
Eva Iryani, M.Sobri, Friscilla \\ evairyani@unja.ac.id, muhammadsobri@unja.ac.id \\ Lecture Department of Study Program education Arabic \\ University Jambi, Indonesia
}

\begin{abstract}
Abstrack: National education aims to develop the potential of students so that they become individuals who have faith and piety to God Almighty, who have a noble attitude, who are healthy, enlightened, capable, creative, independent, and who can become democratic and responsible citizens. With such heavy objectives, all learning activities and processes must support these goals. Campus as one of the educational institutions that have the responsibility to support goals is required and given the task to carry out the Tridarma of Higher Education. And the outputs of Tridarma in the form of research and service must be based on these goals and integrative intelligence. Community service with the socialization of participatory observation learning model was carried out with Madrasah Aliyah 2 Jambi City as a collaborative partner. With the aim that teachers in these schools can actively use innovative and renewable learning models. And further, the socialization efforts support the Ministry of Education and Culture jargon with the concept of free learning. In supporting these efforts to improve, it must be supported by a set of approaches and learning models that can help and reconstruct and realize this large tagline. One of them is through an approach that seeks to involve and optimize all instruments and learning tools that support the independence of the educational process. One such effort is through a participatory observation clarification model.
\end{abstract}

Keywords: integrative intelligence, Free Learning and observation

\section{PENDAHULUAN}

Pendidikan adalah media untuk meningkatkan kualitas sumber daya manusia sehingga orang dapat mengalami kemajuan di berbagai bidang kehidupan mereka. Dalam konteks Indonesia, hal itu tercermin dalam Konstitusi Sistem Pendidikan 
EDU-RILIGIA: Vol. 4 No. 1 Januari - Maret 2020

Nasional Undang-undang Sistem Pendidikan Indonesia tahun 2003, Bab II Pasal 3. Disebutkan bahwa semua unit pendidikan nasional berfungsi untuk mengembangkan keterampilan siswa dan membentuk pola pikir mereka serta peradaban bangsa, yang memiliki martabat yang baik dalam rangka mencerahkan kehidupan bangsa. Sedangkan tujuan pendidikan nasional adalah pengembangan potensi siswa sehingga mereka menjadi individu yang memiliki iman dan takwa kepada Tuhan Yang Maha Esa, yang memiliki sikap luhur, yang sehat, tercerahkan, mampu, kreatif, mandiri, dan yang bisa menjadi warga negara yang demokratis dan bertanggung jawab.

Singkatnya, ada tiga aspek yang perlu dikembangkan menurut sistem pendidikan Indonesia yaitu aspek kognitif, psikomotor, dan afektif. Dalam hal mengembangkan karakter afektif dan moral siswa, pendidikan agama menjadi media utama. Peraturan Pemerintah tentang Pendidikan Agama memilki tujuan mulia "pendidikan agama memiliki fungsi membentuk orang-orang Indonesia yang memiliki iman dan kesalehan yang kuat pada Tuhan Yang Maha Esa dan sikap mulia, dan yang mampu menjaga hubungan yang damai dan tertib di antara mereka dengan agama yang sama atau berbeda". Pentingnya pendidikan agama untuk kehidupan bangsa dapat dilihat ketika pemerintah mewajibkan pendidikan agama diberikan dari tingkat dasar hingga tingkat tersier sebagai mata pelajaran tertentu, dan semua siswa diwajibkan untuk mempelajarinya. Namun demikian, pendidikan perilaku untuk siswa pada lembaga formal melalui pengajaran agama didapati berbagai persoalan dan menyebabkan hasil yang belum tercapai dari tujuan dan fungsi yang dimaksudkan.

Namun, implementasi pendidikan Islam di universitas-universitas Indonesia dikritik karena berorientasi pada kognitif, konvensional, dan karena kurang memberi perhatian pada masalah moral mahasiswa ${ }^{1}$ lokasi waktu yang diberikan kepada mahasiswa dalam mempelajari agamanya pun juga terbatas dalam tingkat universitas. Dalam pelatihan mata kuliah wajib universitas tahun 2019 yang 
Eva Iryani, dkk: Participatory Observation In Madrasah Aliyah As A Reference Of Learning Models In Era 4.0

diadakan oleh LP3M Universitas Jambi disebutkan bahwasanya mahasiswa hanya memiliki total 2-4 SKS untuk mempelajari agama di universitas.

Disisi lain, beberapa kasus moralitas juga sangat menghawatirkan sudah merambat di dunia kaula remaja dan remaja atas. Beberapa kegagalan juga terlihat dalam bentuk terjadinya berbagai masalah moralitas dan karakter di antara para siswa di Provinsi Jambi. ${ }^{2}$ Di Jambi, tercatat pada tahun 2012 silam, aktivis Lembaga Swadaya Masyarakat (LSM) SIKOK Jambi Sumi mengatakan, pihaknya telah melakukan pantauan, survei, hingga inspeksi mendadak (sidak) ke beberapa sekolah di Kota Jambi, mengenai seks bebas di kalangan remaja. Data yang diterima pun naik signifikan.Pada 2012, lebih dari 10 kasus kehamilan yang tidak diinginkan, dan kasus seksual di luar nikah mencapai 30. Sementara itu, sepanjang tahun 2018 di Jambi setidaknya ada 406 laporan kekerasan terhadap perempuan dan anak .3

Jumlah tersebut termasuk angka yang mengejutkan karena peran pemuda sekarang jauh dari apa yang dituliskan dalam tujuan pendidikan.Menurut Muhaimin (2002), ${ }^{4}$ terjadinya masalah moral yang disebutkan di atas di kalangan remaja Muslim di Indonesia adalah, antara lain, karena pendekatan yang tidak sesuai dari Kursus Pendidikan Islam di Indonesia, subjek studi bernama Pendidikan Agama Islam (Program Pendidikan Islam), yang disingkat PAI, dengan tujuannya. Ini juga karena model pengajaran PAI cenderung konvensional dan lebih fokus pada pengembangan aspek kognitif siswa.

Kemerdekaan belajar haruslah dimulai dari Guru yang merdeka pula. guru yang merdeka adalah guruyang mampu menerjemahkan kurikulum, mencari jalan keluar secara mandiri terhadap problematika pembelajaran. Dan selanjutnya kemerdekaan belajar itu diteruskan terhadap peserta didik. Bahkan Nadiem menuturkan: semua guru harus berpikir secara mandiri, pembelajaran tidak akan terjadi jika hanya administrasi pendidikan yang akan terjadi. "Paradigma merdeka belajar adalah untuk menghormati perubahan yang harus terjadi agar pembelajaran 
EDU-RILIGIA: Vol. 4 No. 1 Januari - Maret 2020

itu mulai terjadi diberbagai macam sekolah. ${ }^{5}$ Dalam mendukung upaya peningkatan tersebut, haruslah didukung dengan seperangkat pendekatan dan model pembelajaran yang dapat membantu dan merekonstruk serta mewujudkan tagline besar tersebut. Salah satunya melalu pendekatan yang berupaya melibatkan dan mengoptimalkan seluruh instrumen dan perangkat pelajaran yang mendukung kemerdekaan proses pendidikan. Salah satu upaya tersebut adalah melalui model pemebelajran observasi partisipatori. Untuk itu perlu adanya kegiatan dalam bentuk Sosialisasi Partisipatory Observation di Madrasah Aliyah 2 Kota Jambi sebagai referensi pembelajaran di era 4.0.

\section{LANDASAN TEORI}

\section{Kampus Merdeka Belajar}

Pemerintah dengan berbagai upaya lewat program telah melaksanakan peningkatkan mutu pendidikan di Indonesia. Wujud Peningkatan pendidikan tersebut di terjemahkan lewat Tagline "Merdeka belajar" oleh menteri pendidikan dan kebudayaan yang mulai digaungkan ketika hari guru Nasional 2019. Merdeka belajar adalah kemerdekaan berpikir. Keutamaan esensi dari kemerdekaan berpikir ini harus ada di guru dulu. Tanpa terjadi di guru, tidak mungkin bisa terjadi di murid." Dan upaya memperbaiki mutu pendidikan lewat peningkatan kualitas guru baik. Melalui upaya diklat pendidikan dan pelatihan sebagai edukasi program yang sesuai dengan tuntutan pendidikan Abad 21.

Dan proses pembelajaran dalam kampus merdeka merupakan satu perwujudan pembelajaran yang berpusat kepada mahasiswa (student centered learning) yang sangat esensial. Pembelajaran dalam kampus merdeka memberi tantangan dan kesempatan untuk pengembangan kreativitas, kapasitas, kepribadian, dan kebutuhan mahasiswa, serta mengembangkan kemandirian dalam mencari dan menemukan pengetahuan. ${ }^{6}$ 
Eva Iryani, dkk: Participatory Observation In Madrasah Aliyah As A Reference Of Learning Models In Era 4.0

Kemerdekaan belajar haruslah dimulai dari guru yang merdeka pula. Guru yang merdeka adalah guruyang mampu menerjemahkan kurikulum, mencari jalan keluar secara mandiri terhadap problematika pembelajaran. Dan selanjutnya kemerdekaan belajar itu diteruskan terhadap peserta didik. Bahkan Nadiem menuturkan: semua guru harus berpikir secara mandiri, pembelajaran tidak akan terjadi jika hanya administrasi pendidikan yang akan terjadi. "Paradigma merdeka belajar adalah untuk menghormati perubahan yang harus terjadi agar pembelajaran itu mulai terjadi diberbagai macam sekolah. ${ }^{7}$

\section{Observasi Partispatori}

mendukung upaya peningkatan kualitas pendiidkan tersebut, haruslah didukung dengan seperangkat pendekatan dan model pembelajaran yang dapat membantu dan merekonstruk serta mewujudkan tagline besar tersebut. Salah satunya melalu pendekatan yang berupaya melibatkan dan mengoptimalkan seluruh instrumen dan perangkat pelajaran yang mendukung kemerdekaan proses pendidikan. Salah satu upaya tersebut adalah melalui model pemebelajran observasi partisipatori.

Observasi Partisipatoribertujuan untuk menggambarkan model pengajaran yang meningkatkan karakter keagamaan dan sosial siswa. selanjutyaobservasi partisipatori sebagai model pengajaran Pendidikan agama Islam adalah untuk menilai validitas, kepraktisan, dan efektivitas model. Dengan menggunakan langkah-langkah modifikasi dari penelitian pengembangan Plomp, penelitian menghasilkan sintaksis model pengajaran yang terdiri dari tujuh langkah, yaitu a) orientasi, b) identifikasi dan menemukan "mitra belajar" c) pengamatan awal, d) pengamatan, d) memberikan hadiah, e) refleksi, f) membuat laporan, dan g) presentasi. ${ }^{8}$ Yang dari ketujuh langkah model tersebut diharapkan agar pendidik dapat meningkatkan pembelajaran berbasis kecerdasan integrative yang terdiri dari Intelektual, emosional dan spiritual. 
Eva Iryani, dkk: Participatory Observation In Madrasah Aliyah As A Reference Of Learning Models In Era 4.0

model pengajaran tersebut terdiri dari pola dan rencana yang dapat digunakan untuk membentuk kurikulum khusus, memilih bahan dan materi yang tepat, dan selanjutnya membimbing tindakan kelas terhadap pendidik. ${ }^{9}$ Dalam perspektif klasifikasi Joyce dan Weill untuk model pengajaran. ${ }^{10}$ "Pengamatan Partisipatif dalam Islam Model pengajaran Education" termasuk dalam kategori sosial model pengajaran. Itu karena interaksi sosial dengan anggota masyarakat (dalam model ini, mitra belajar yang pekerjaannya adalah dipandang rendah dan sulit oleh masyarakat) adalah pusat dari "Observasi Partisipatif dalam Pendidikan Islam". Sebagai tambahan, siswa yang belajar dalam kelompok menemukan nilainilai kesabaran, terima kasih, empati, dan rasa hormat melalui interaksi mereka dengan mitra belajar mereka. Proses ini setuju dengan deskripsi model pengajaran sosial menurut Joyce dan Weill of yang fungsinya meningkatkan kehidupan sosial dan pribadi. Selain itu, berdasarkan perspektif cara siswa mendapatkan pengetahuan dan meningkatkan karakter sosial dan keagamaan mereka, model pengajaran "Observasi Partisipatif dalam Islam Pendidikan" menggunakan filosofi konstruktivisme. Dalam filosofi konstruktivisme, para siswa tidak mendapatkan pengetahuan dalam bentuk produk akhir tetapi mereka perlu mengatur itu sendiri melalui proses pembelajaran. ${ }^{11}$

Model Ini membimbing guru selama kegiatan pembelajaran secara sistematis dan efektif berdasarkan pada tujuan pembelajaran, kondisi siswa, waktu yang tersedia, dan media pembelajaran. Dan dengan melibatkan seluruh siswa untuk melaksanakan pengamatan dengan berpartisipasi langsung dalam lingkungan social kemasyrakatan berbasis pelajaran agama islam di sekolah demi mengasah beberapa kecerdasan yang tidak disalurkan di dalam kelas. Model pengajaran yang dikembangkan dalam ini disebut sebagai "Pengamatan Partisipatif dalam Pendidikan Islam" karena mengharuskan siswa untuk mengamati dan berpartisipasi dalam kegiatan tertentu yang dirancang sebagai bagian dari pengajaran Islam. 
Eva Iryani, dkk: Participatory Observation In Madrasah Aliyah As A Reference Of Learning Models In Era 4.0

\section{METODE PELAKSANAAN}

\section{Metode Kegiatan}

Metode yang digunakan dalam pelaksanaan Sosialisasi Participatory Observation di Madrasah Aliyah Negeri 2 Kota Jambi Sebagai Referensi Model Pembelajaran di Era 4.0 adalah sebagai berikut:

\section{Metode Ceramah dan Diskusi.}

Pelaksanaan kegiatan dilakukan secara langsung mengenai pengertian, manfaat, tujuan dari partisipatory observation ini dan peran pemuda saat ini dalam menghadapi tantangan era 4.0. Peningkatan pengetahuan peserta pelatihan dilakukan dengan pemberian materi melalui pendekatan ceramah dan diskusi.

\section{Demonstrasi}

Pada kegiatan ini mahasiswa diberikan kesempatan untuk menerapkan partisipatory observation, tentunya dalam pengawasan tim. Dari kegiatan ini dapat dilihat sejauh mana mahasiswa peka dalam mengoptimalkan karakter keagamaan dan sosial di dalam lingkungannya

\section{Focus Group Discussion}

Setelah mahasiswa diberikan pemahaman, dan praktek langsung menggunakan metode partisipatory observation ini ${ }_{s}$ maka tim akan mengumpulkan kembali mahasiswa kemudian mendengarkan laporan serta kesan mahasiswa setelah mereka terlibat dalam metode ini di lingkungannya.

\section{HASIL DAN PEMBAHASAN}

\section{Hasil}

Pada bagian ini akan dibahas secara singkat terkait hasil dan pemabahasan atas pelaksanaan kegiatan pengabdian pada masyarakat yang dilaksakan di MAN 2 Kota Jambi. Dengan rincian pelaksanaan sebagai berikut :

Pelaksanaan kegiatan Sosialisasi Participatory Observation di Madrasah Aliyah Negeri 2 Kota Jambi Sebagai Referensi Model Pembelajaran di Era 4.0: 
EDU-RILIGIA: Vol. 4 No. 1 Januari - Maret 2020

\author{
Hari/Tanggal : 23 Juli 2020 \\ Waktu :09.00- selesai \\ Tempat : MAN 02 Kota Jambi \\ Agenda : Sosialisasi model pembelajaran observasi partisipatory \\ Instruktur : : Eva Iryani,S.Pd.I., M.Pd.I \\ Muhammmad Sobri. S.Pd.I., M.Pd \\ Friscilla Wulan Tertsa. M.Pd
}

Dan hasil pada kegiatan tersebut tercermin dari sasaran kegiatan yaitu peningkata pemahaman terhadap model pembelajaran Participatory Observation sebagai bentuk penunjang pembelajaran yang inovatif dan meningkatkan partisipasi siswa dalam belajar. Dan terkhusus pada guru dapat menerapkan model pembelajaran tersebut dalam mengimplementasikan kurikulum merdeka belajar.

\title{
Pembahasan
}

Kegiatan pelaksanaan Pengabdian Pada Masyarakat (PPM) ini merupakan salah satu kewajiban yang diberikan kepada dosen di perguruan tinggi. Dalam mewujudkan tri darma perguruan tinggi yang diembannya. Dan kegiatan sosialisasi ini dilaksanakan secara mandiri oleh tim dosen pendidikan bahasa arab universitas jambi. Dengan tetap melalui prosedur pengajuan penelitian di LPPM universitas jambi. Dalam hal ini mitra yang bekerjjasama adalah salah satu sekolah favorit di kota jambi yakni, MAN 2 Kota Jambi.

Dalam pengabdian ini tentulah mempunyai target dan sasaran pengabdian yang diharapkan dapat bermanfaat bagi universitas, mitra dan masyarakat luas. Dan terpenting bagi guru agar menjadi Problem Solver dan dapat menemukan solusi terkait pembelajaran yang cenderung kaku dan monoton.

Adapun pelaksanaan kegiatan pelatihan penulisan jurnal ilmih ini sebagaimana adalah sebagai berikut: 
Eva Iryani, dkk: Participatory Observation In Madrasah Aliyah As A Reference Of Learning Models In Era 4.0

Tabel 5.1 Pelaksanaan Kegiatan Pelatihan

\begin{tabular}{|c|c|c|c|c|}
\hline $\begin{array}{l}\text { Langkah- } \\
\text { langkah }\end{array}$ & Materi & Metode & $\begin{array}{c}\text { Partisipasi } \\
\text { Guru }\end{array}$ & $\begin{array}{c}\text { Indikator } \\
\text { Keberhasilan }\end{array}$ \\
\hline 1 & $\begin{array}{l}\text { Memaparkan } \\
\text { urgensi model } \\
\text { dan metode, } \\
\text { serta } \\
\text { kebutuhan } \\
\text { pembelajaran } \\
\text { di Era } 4.0\end{array}$ & $\begin{array}{l}\text { Persentasi, } \\
\text { diskusi, dan } \\
\text { demonstrasi }\end{array}$ & $\begin{array}{l}\text { Mendengarkan } \\
\text { dan } \\
\text { memperhatikan } \\
\text { dengan } \\
\text { seksama. }\end{array}$ & $\begin{array}{l}\text { Guru guru } \\
\text { memperhatikan } \\
\text { dengan baik } \\
\text { dan fokus. }\end{array}$ \\
\hline 2 & $\begin{array}{l}\text { Memberikan } \\
\text { pemaparan } \\
\text { mengenai } \\
\text { approach, method, } \\
\text { dan techniques } \\
\text { selaku pondasi } \\
\text { dasar bagi guru } \\
\text { untuk } \\
\text { membedakan } 3 \\
\text { aspek tersebut. }\end{array}$ & $\begin{array}{l}\text { Persentasi } \\
\text { dan diskusi }\end{array}$ & $\begin{array}{l}\text { Mendengarkan } \\
\text { dan } \\
\text { memperhatikan } \\
\text { dengan } \\
\text { seksama. }\end{array}$ & $\begin{array}{l}\text { Guru dapat } \\
\text { membedakan } 3 \\
\text { aspek tersebut. }\end{array}$ \\
\hline 3 & $\begin{array}{l}\text { Paparan } \\
\text { obsevasi } \\
\text { partipatori } \\
\text { sebagai variasi } \\
\text { pembelajaran } \\
\text { yang dapat } \\
\text { guru terapkan } \\
\text { di kelas dan } \\
\text { diluar kelas }\end{array}$ & Diskusi & $\begin{array}{l}\text { Mendengarkan } \\
\text { dan } \\
\text { memperhatikan } \\
\text { dengan } \\
\text { seksama. }\end{array}$ & $\begin{array}{l}\text { Guru dapat } \\
\text { lebih kreatif } \\
\text { dalam } \\
\text { mengajarkan } \\
\text { Bahasa Arab di } \\
\text { kelas. }\end{array}$ \\
\hline 4 & $\begin{array}{l}\text { Tanya Jawab, } \\
\text { sharing session } \\
\text { seputar } \\
\text { permasalah } \\
\text { penmebelajaran }\end{array}$ & Diskusi & Tanya-Jawab & $\begin{array}{l}\text { Adanya umpan } \\
\text { balik dan } \\
\text { refleksi dari } \\
\text { hasil } \\
\text { pengajaran } \\
\text { selama ini. }\end{array}$ \\
\hline
\end{tabular}

Pentingnya model pembelajaran baru sama pentingnya dengan menerapkan ekspresi, kreatifitas dan inovasi baru. Guru dalam hal ini haruslahh setiap saat meningkat kompetensinya agar siswa dapat umpan balik pembelajaran 
EDU-RILIGIA: Vol. 4 No. 1 Januari - Maret 2020

yang sulit ditemui pada kurikulum sebelum dijadikannya siswa sebagai pusat belajar. Dan model observasi partisipatori adalah salah satu solusi atas kendala tersebut.

\section{KESIMPULAN DAN SARAN}

\section{Kesimpulan}

sosialisasi atau pelatihan sangatlah besar manfaat bagi penyebarluasan ilmu pengetahuan. Maka dalam penyebaran dan penambahan serta peningkatan kapasitas guru disekolah haruslah perguruan tinggi menggalakkan sosialisasi model-model pembelajaran baru seperti halnya. Observasi partisipatori ini dikarenakan tuntutan revolusi 4.0 yang menuntut serba cepat dan efektif.

\section{Saran}

Mengingat besarnya manfaat kegiatan pengabdian pada masyarakat ini, maka perlu :

1) Mengadakan pelatihan yang sama secara masiv terhadap sekolah lain dengan khalayak sasaran yang lebih banyak

2) Setelah diadakan sosialisasi ini diharapkan para guru dapat terus menggali model dan ide dalam pembelajaran bahasa Arab agar hasil yang diingikan dapat tercapai.

\section{Endnote:}

${ }^{1}$ Nasih, A. M., Sultoni, A., \& Fuad, A. Z. (2017, October). Model of Teaching "Participatory Observation in Islamic Education" to Improve Religious and Social Characters of University Students: a Preliminary Research. In International Conference on Learning Innovation (ICLI 2017). Atlantis Press.

2 https://www.tribunnews.com/regional/2013/03/06/10-persen-remaja-wanita-jambitidak-perawan

3 https://news.okezone.com/read/2019/01/02/340/1999003/catatan-sepanjang-2018kasus-pelecehan-seksual-di-kalangan-pelajar-jambi-meningkat

${ }^{4}$ M. Muhaimin, Paradigma Pendidikan Islam. Bandung: PT Remaja Rosdakarya, 2002.

5https://www.msn.com/id-id/berita/nasional/nadiem-makarim-merdeka-belajaradalah kemerdekaan-berpikir/ar-AAK5PAy 
EDU-RILIGIA: Vol. 4 No. 1 Januari - Maret 2020

${ }^{6}$ Dirjen Pendidikan Tinggi, "Buku saku merdeka dan kampus merdeka", edisi ke-satu, (Jakarta,2020).h. 4

7https://www.msn.com/id-id/berita/nasional/nadiem-makarim-merdeka-belajaradalah kemerdekaan-berpikir/ar-AAK5PAy

8 Nasih, A. M., Sultoni, A., \& Fuad, A. Z. Model of Teaching "Participatory Observation in Islamic Education" to Improve Religious and Social Characters of University Students: a Preliminary Research. In International Conference on Learning Innovation (ICLI 2017). Atlantis Press

${ }^{9}$ Nasih, A. M., Sultoni, A., \& Fuad, A. Z, "Model of Teaching" h. 105-106

${ }^{10}$ B. Joyce and W. Marsha, Models of Teaching, Fifth Edit. New Delhi: Prentice Hall, 2003. h.201

${ }^{11}$ C. Bereiter, "Constructivism, socioculturalism, and Popper's world 3," Educ. Res., vol. 23, no. 7, pp. 21-23, 1994. 
EDU-RILIGIA: Vol. 4 No. 1 Januari - Maret 2020

\section{Daftar Pustaka}

B. Joyce and W. Marsha, Models of Teaching, Fifth Edit. New Delhi: Prentice Hall, 2003.

C. Bereiter, Constructivism, socioculturalism, and Popper's world 3, Educ. Res., vol. 23, no. 7.1994

Dirjen Pendidikan Tinggi, Buku Saku Merdeka dan Kampus Merdeka, edisi ke-satu, (Jakarta, 2020).

M. Muhaimin, Paradigma Pendidikan Islam. Bandung: PT Remaja Rosdakarya, 2002.

Nasih, A. M., Sultoni, A., \& Fuad, A. Z. (2017, October). Model of Teaching"

Participatory Observation in Islamic Education" to Improve Religious and Social

Characters of University Students: a Preliminary Research. In International

Conference on Learning Innovation (ICLI 2017). Atlantis Press.

https://www.tribunnews.com/regional/2013/03/06/10-persen-remaja-wanitajambi-tidak-perawan

https://news.okezone.com/read/2019/01/02/340/1999003/catatan-sepanjang-

2018-kasus-pelecehan-seksual-di-kalangan-pelajar-jambi-meningkat

https://www.msn.com/id-id/berita/nasional/nadiem-makarim-merdeka-

belajaradalah kemerdekaan-berpikir/ar-AAK5PAy 